\title{
Crohn's disease of the colon with Takayasu's arteritis
}

\author{
S. J. LENHOFF \\ M.B., Ch.B.
}

\author{
A. S. MeE \\ M.D., M.R.C.P.
}

The Gastrointestinal Clinic, Groote Schuur Hospital and The Department of Medicine, University of Cape Town, Cape Town, South Africa

\begin{abstract}
Summary
A case of Crohn's disease of the colon with Takayasu's arteritis in a young woman is presented. A possible pathogenetic mechanism whereby circulating immune complexes associated with Takayasu's arteritis could lead to a chronic colitis is proposed.
\end{abstract}

\section{Introduction}

Both Crohn's disease of the colon and Takayasu's arteritis are relatively uncommon disorders and the aetiology of both conditions remains unknown. Since the likelihood of their simultaneous occurrence is extremely small we wish to report such an association and in view of this and previous case reports propose a possible pathogenetic mechanism by which both diseases might arise in the same subject.

\section{Case report}

A 24-year-old woman who was previously fit and playing competition softball presented with a 3month history of lower abdominal cramps and the passage of profuse watery diarrhoea without blood. Three weeks before admission she had noticed painful swelling of both knees and pain on movement of both ankles and the right wrist. Over the period of her illness she had lost $19 \mathrm{~kg}$ in weight. There were no symptoms referable to the cardiovascular system. She smoked 5 cigarettes per day and was not taking oral contraceptives.

Examination revealed a pale but otherwise healthy-looking woman with a temperature of $37 \cdot 2^{\circ} \mathrm{C}$. The left carotid, upper and lower limb arteries were all diminished and there was a systolic thrill palpable over the right carotid artery. Blood pressure was $120 / 65 \mathrm{mmHg}$ in the right arm, 90/70 $\mathrm{mmHg}$ in the left arm and $145 / 90 \mathrm{mmHg}$ in the lower limbs. Bruits were audible over both right and left carotid arteries and over the abdominal aorta.

Correspondence: Dr A. S. Mee, Department of Gastroenterology, Central Middlesex Hospital, Acton Lane, London NW10 7NS, England.

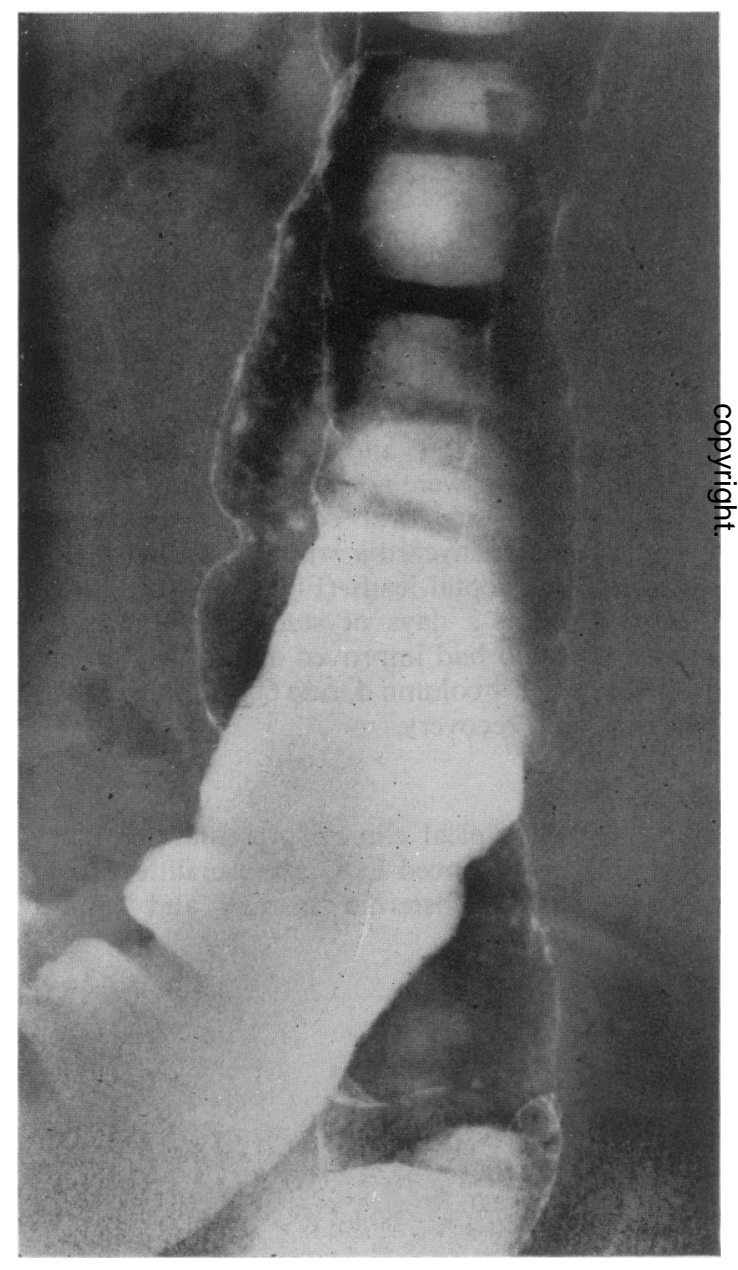

FIG. 1. Detail from double contrast barium enema which shows a diffuse colitis with shallow ulceration.

There were slight effusions of both knees. The rest of the examination was normal. 
Investigations: $\mathrm{Hb} 10.9 \mathrm{~g} / \mathrm{dl}$, WBC $20.3 \times 10^{\%} / 1$, ESR $41 \mathrm{~mm} / 1 \mathrm{st}$ hour, alkaline phosphatase $97 \mathrm{u} . / \mathrm{l}$ (30-85), albumin $27 \mathrm{~g} / \mathrm{l}$, serum iron $3.0 \mu \mathrm{mol} / 1$ (total iron-binding capacity (TIBC) $51 \mu \mathrm{mol} / \mathrm{l}$ ) serum folate $4.3 \mathrm{mg} / \mathrm{ml}(4.8-16.0)$, anti-nuclear factor (ANF) $1: 10$, serological tests for syphilis-negative, lipid profile, C3 and immunoglobulins within normal limits. Hepatitis B surface antigen, immune complexes (Clq binding technique) and cryoglobulins not detected. Stool culture-no pathogens isolated. Sigmoidoscopy showed a hyperaemic rectal mucosa with scattered aphthoid ulceration. Double contrast barium enema demonstrated a total colitis with mucosal irregularity and aphthoid ulceration (Fig. 1). Barium meal and follow-through was normal.

Colonoscopy confirmed the radiological features of total colonic involvement with scattered small aphthoid ulcers. Rectal and colonoscopic biopsies showed a non-specific mononuclear cell infiltrate with focal superficial ulceration and relative preservation of gland architecture.

Aortography revealed a markedly narrowed left

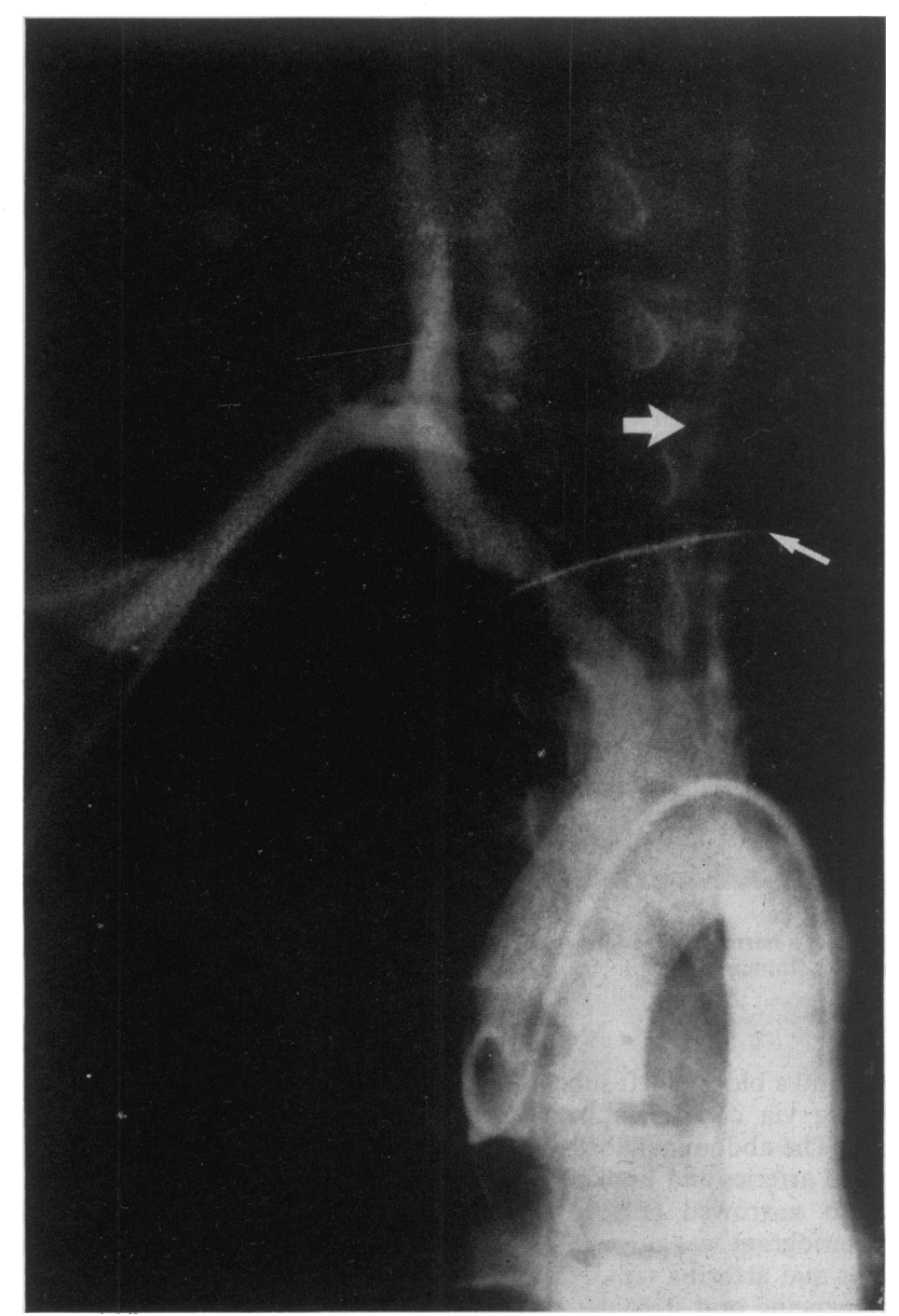

FIG. 2. Arch aortogram demonstrating a markedly narrowed left common carotid artery (thick arrow) and a blocked left subclavian artery (thin arrow). 


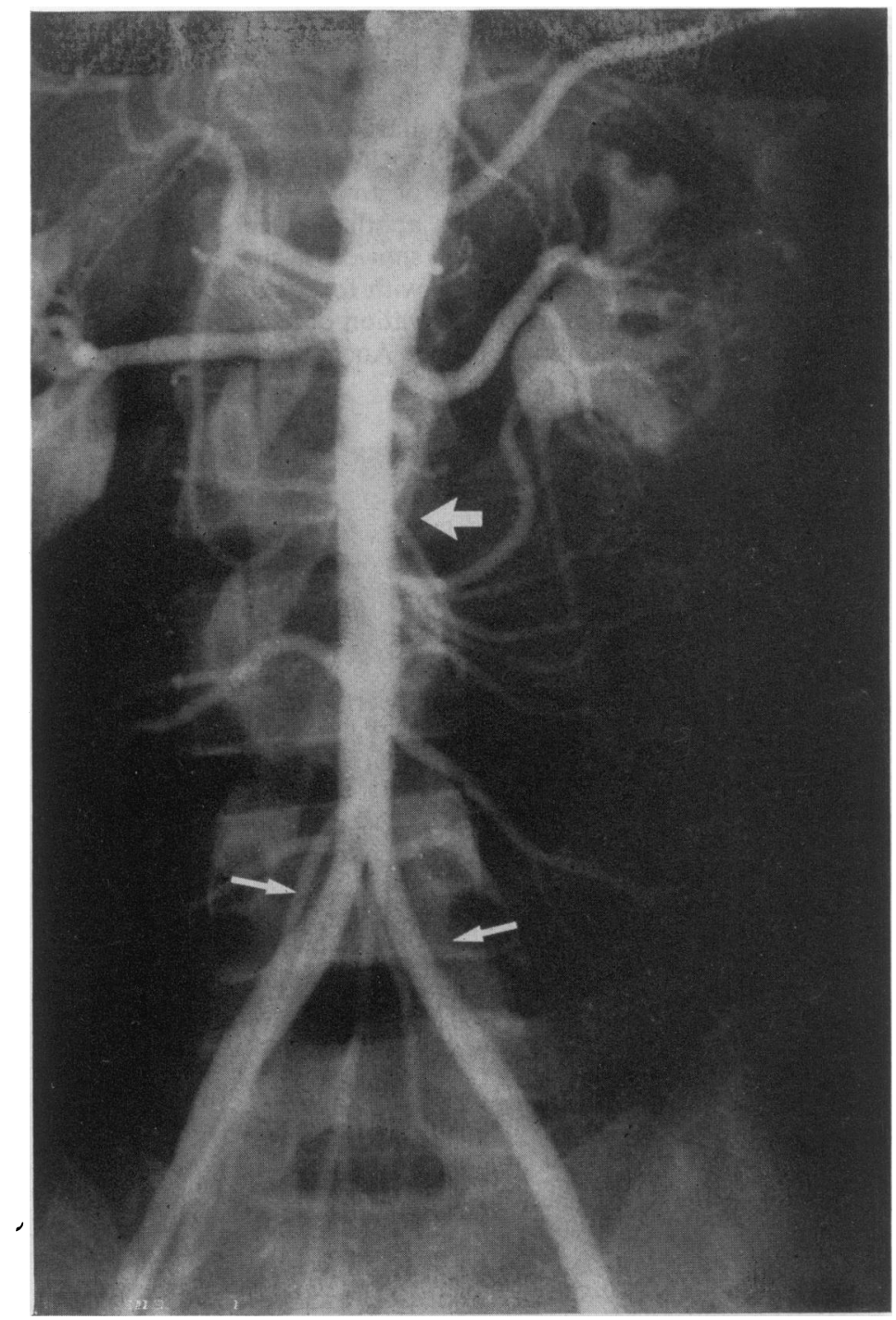

FIG. 3. Flush aortogram shows a narrowed abdominal aorta distal to the origin of the renal arteries (thick arrow) and narrowing of both common iliac arteries (thin arrows).

common carotid artery and a blocked left subclavian artery with distal filling via collaterals from the scapular artery (Fig. 2). The abdominal aorta, distal to the origin of the renal arteries and both common iliac arteries were also narrowed (Fig. 3). The superior mesenteric arteriogram was normal.

Her bowel symptoms and arthritis rapidly settled within a week of commencing oral steroids.

\section{Discussion}

The likelihood of both diseases occurring by chance in this patient is approximately 1 in $5 \times 10^{9}$. Since Takayasu's arteritis occurring in conjunction with both Crohn's disease of the colon and ulcerative colitis has been reported previously it would seem probable that there is a significant association between the three diseases (Chapman et al., 1978; Owyang et al., 1979; Friedman \& Tegtmeyer, 1979).

Although neither skip lesions nor granulomata were present in this patient the clinical, radiographic, colonscopic and histological features fit best the diagnostic category of Crohn's disease of the colon 
since no other recognized disease pattern, in particular mesenteric ischaemia, is capable of causing such a combination of abnormalities.

Immune complexes (by a single technique) could not be demonstrated in this patient's serum. This was however 3 days after she had been started on steroids and may not therefore have been an accurate reflection of her status before starting treatment. Furthermore it has previously been demonstrated that circulating immune complexes occur in over $50 \%$ of patients with Takayasu's arteritis (DiazJouanen et al., 1980). It has also been shown that circulating immune complexes are capable of localizing to a mildly irritated colonic mucosa and inducing a chronic immune colitis in rabbits previously sensitized to a common enterobacterial antigen (Mee et al., 1979). We propose therefore that circulating immune complexes associated with Takayasu's arteritis may localize to the colon of some susceptible individuals where they give rise to a chronic colitis as in our patient.

\section{Acknowledgment}

We are grateful to Dr A. H. Girdwood who kindly referred the patient.

\section{References}

Chapman, R., Dawe, C., Whorwell, P.J. \& Wright, R. (1978) Ulcerative colitis in association with Takayasu's disease. Digestive Disease and Sciences, 23, 660.

Owyang, C., Miller, L.J., Lie, J.T. \& Fleming, C.R. (1979) Takayasu's arteritis in Crohn's disease. Gastroenterology, 76, 825.

Friedman, C.J. \& Tegtmeyer, C.J. (1979) Crohn's disease associated with Takayasu's arteritis. Digestive Diseases and Sciences, 24, 54.

Diaz-Jouanen, E., Salazar, J.F., Abud-Mendoza, C. \& Alarćon-Segovia, D. (1980) Immune complexes in autoimmune diseases. Revista de Investigación Clinica, 32, 153.

Mee, A.S., Mclaughlin, J., Hodgson, H.J.F. \& Jewell, D.P. (1979) Chronic immune colitis in rabbits. Gut, $20,1$. 